ISSN 1420-3049

www.mdpi.com/journal/molecules

Article

\title{
A Novel 18-Norclerodane Diterpenoid from the Roots of Tinospora sagittata var. yunnanensis
}

\section{Xiang-Zhong Huang ${ }^{1}$, Chun-Mei Cheng ${ }^{1}$, Yun Dai ${ }^{1}$, Guang-Miao Fu ${ }^{2, *}$, Jun-Ming Guo ${ }^{1}$, Yan Yin ${ }^{1}$ and Hui Liang ${ }^{1}$}

1 Key Laboratory of Ethnic Medicine Resource Chemistry, School of Chemistry and Biotechnology, Yunnan University of Nationalities, Kunming 650031, China

2 School of Pharmacy, Henan College of Traditional Chinese Medicine, Zhengzhou 450008, China

* Author to whom correspondence should be addressed; E-Mail: fugmiao@yahoo.com.cn; Tel.: +86-371-6568-0011; Fax: +86-371-6568-0011.

Received: 10 September 2010; in revised form: 4 November 2010 / Accepted: 10 November 2010 / Published: 16 November 2010

\begin{abstract}
A novel 18-nor-clerodane diterpenoid named sagitone (1) was isolated from the 95\% ethanol extract of dry roots of Tinospora sagittata var. yunnanensis together with the five known diterpenoids columbin (2), palmatoside C (3), fibleucin (4), tinophylloloside (5) and epitinophylloloside (6). The structure of the new compound $\mathbf{1}$ was determined based on MS, IR, 1D and 2D NMR spectral data. The compounds 1 6 did not show significant cytotoxic activity against cancer cell lines K562 and HL-60.
\end{abstract}

Keywords: Tinospora sagittata var. Yunnanensis; clerodane diterpenoid; sagitone; cytotoxic activity

\section{Introduction}

The clerodane diterpenoids occupy a unique and important place in the natural product field, because of their widespread distribution, extensive structural variation, and pronounced biological properties such as cytotoxic, antibacterial and antimicrobial activity [1-4]. Most species of the genus Tinospora (Menispermaceae) are among the most widely employed medicinal plants throughout a large part of Asia and Africa, and the characteristic constituents of this genus are the clerodane-based furnoid diterpenoids [5,6]. Tinospora sagittata var. yunnanensis, a member of family Menispermaceae, 
is a special plant native to Yunnan and Guangxi Province, China. The roots of $T$. sagittata var. yunnanensis has been used for thousands of years in Traditional Chinese Medicine for treating sore throat, laryngitis, gastralgia, and diarrhea [7]. Previous phytochemical investigation on the roots of $T$. sagittata var. yunnanensis revealed a number of alkaloids and clerodane-type diterpeneoids [8]. In the present study, we describe the isolation and structure elucidation of a novel 18-nor-clerodane diterpenoid, named sagitone (1), together with five known diterpenoids, columbin (2), palmatoside C (3), fibleucin (4), tinophylloloside (5) and epitinophylloloside (6), from the 95\% ethanol extract of the dry roots of $T$. sagittata var. yunnanensis (Figure 1). The structure of the new compound 1 was determined based on MS, IR, 1D and 2D NMR spectral data, and the known ones 2-6 were identified by comparing their NMR data with those in the literature. All compounds did not show considerable inhibitory cytotoxic activity against cancer cell lines K562 and HL-60 at a concentration of $10 \mu \mathrm{M}$.

Figure 1. The structures of compounds 1-6.

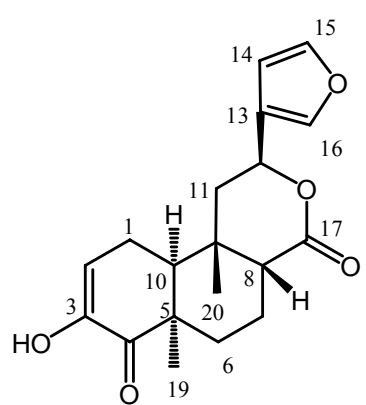

1

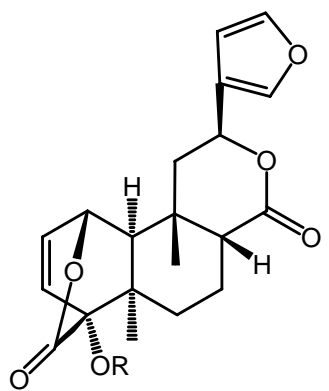

$2 \mathbf{R}=\mathbf{H}$

$3 \mathbf{R}=\overbrace{\mathrm{HO}}^{\mathrm{O}} \mathrm{TOH}_{\mathrm{OH}}^{\mathrm{OH}}$

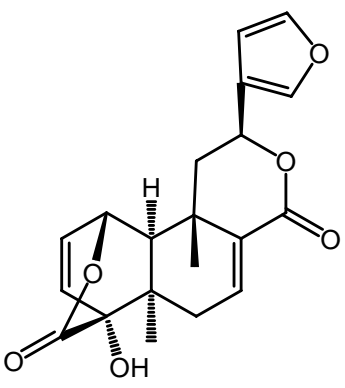

4
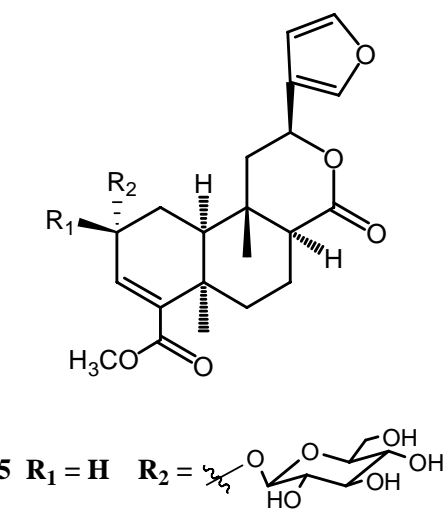

$6 \mathbf{R}_{\mathbf{1}}=\psi_{2}^{\mathrm{O}} \underbrace{\mathrm{O}}_{\mathrm{HO}} \mathrm{COH}_{\mathrm{OH}}^{\mathrm{OH}} \mathbf{R}_{\mathbf{2}}=\mathbf{H}$

\section{Results and Discussion}

Compound 1 was obtained as an amorphous powder and with positive reaction in the $10 \%$ $\mathrm{H}_{2} \mathrm{SO}_{4}$-EtOH test. The molecular formula was deduced from a pseudo-molecular ion $[\mathrm{M}+\mathrm{H}]^{+}$at $m / z 331.3816$ in the HR-ESI-MS (calcd. for $\mathrm{C}_{19} \mathrm{H}_{23} \mathrm{O}_{5}, 331.3829$ ), which was in agreement with the ${ }^{1} \mathrm{H}-\mathrm{NMR},{ }^{13} \mathrm{C}-\mathrm{NMR}$ and DEPT spectra (Table 1). The IR spectrum showed characteristic absorption bands for hydroxyl group $\left(3,407 \mathrm{~cm}^{-1}\right), \delta$-lactone carbonyl $\left(1,710 \mathrm{~cm}^{-1}\right), \alpha, \beta$-unsaturated ketone $\left(1,672 \mathrm{~cm}^{-1}\right)$ and furan $\left(874 \mathrm{~cm}^{-1}\right)$ functions. Additionally, a strong absorption bond at $238 \mathrm{~nm}$ in the UV spectrum also suggested the presence of an $\alpha, \beta$-unsaturated ketone group.

The ${ }^{1} \mathrm{H}-,{ }^{13} \mathrm{C}-\mathrm{NMR}$ and DEPT spectra of compound $\mathbf{1}$ (Table 1) revealed 19 carbons, consisting of two methyls, four methylenes, seven methines, and six quaternary carbons. Taking into account the nine degrees of unsaturation, compound 1 should include four rings. Careful analysis of its ${ }^{1} \mathrm{H}-$ and ${ }^{13} \mathrm{C}-\mathrm{NMR}$ data strongly suggested that the compound exhibited typical clerodane diterpenoid signals. The characteristic ${ }^{1} \mathrm{H}$ - and ${ }^{13} \mathrm{C}$-NMR signals of 1 revealed the existence of a $\beta$-substituted furan ring $(\delta 6.42 \mathrm{~s}, 7.43 \mathrm{~s}$ and $7.45 \mathrm{~s} ; \delta 108.4,143.8,139.6,125.0)$. The one proton double doublet at $\delta 5.42$ $(J=12.4,4.0 \mathrm{~Hz})$ was assigned to the $\mathrm{C}-12$ proton and two one-proton double doublets at $\delta 2.30$ $(J=14.8,4.0 \mathrm{~Hz})$ and $1.73(J=14.8,12.0 \mathrm{~Hz})$ were attributed to the $\mathrm{C}-11$ eq and $\mathrm{C}-11 \mathrm{ax}$ protons, 
respectively. The presence of a carbinolic carbon was also evident from ${ }^{13} \mathrm{C}-\mathrm{NMR}$ signal at $\delta 70.6$ (C-12). The two methyl groups at C-9 and C-5 were observed as three proton singlets at $\delta 1.30$ and 0.96 , respectively. The signals at $\delta 2.30$ and 2.20 were assigned to the protons at $\mathrm{C}-8$ and $\mathrm{C}-10$, and the C-6 and C-7 methylene protons resonating at $\delta 2.40(\mathrm{~m}), 1.19(\mathrm{dt}, J=14.0,4.0 \mathrm{~Hz})$ and 2.25 (m), $1.61(\mathrm{~m})$, respectively.

Table 1. ${ }^{1} \mathrm{H}$ - and ${ }^{13} \mathrm{C}-\mathrm{NMR}$ data of $\mathbf{1}$ in $\mathrm{CDCl}_{3}$. $\left({ }^{1} \mathrm{H}\right.$ at 400 and ${ }^{13} \mathrm{C}$ at $100 \mathrm{MHz} ; J$ in $\left.\mathrm{Hz}\right)$.

\begin{tabular}{|c|c|c|c|c|}
\hline Position & $\delta \mathrm{C}$ & DEPT & $\delta \mathbf{H}$ & HMBC \\
\hline \multirow{2}{*}{1} & \multirow{2}{*}{20.8} & \multirow{2}{*}{$\mathrm{CH}_{2}$} & $2.87(\mathrm{~m})$ & \multirow{2}{*}{$C-3,5,9,10$} \\
\hline & & & $2.30(\mathrm{~m})$ & \\
\hline 2 & 112.4 & $\mathrm{CH}$ & $5.86(\mathrm{~m})$ & $\mathrm{C}-3,4,10$ \\
\hline 3 & 145.7 & $\mathrm{C}$ & & \\
\hline 4 & 198.9 & $\mathrm{C}$ & & \\
\hline 5 & 44.3 & $\mathrm{C}$ & & \\
\hline \multirow{2}{*}{6} & \multirow{2}{*}{29.4} & \multirow{2}{*}{$\mathrm{CH}_{2}$} & $2.40(\mathrm{~m})$ & \multirow{2}{*}{$\mathrm{C}-8,19$} \\
\hline & & & $1.19(\mathrm{dt}, 14,4.0 \mathrm{~Hz})$ & \\
\hline \multirow{2}{*}{7} & \multirow{2}{*}{19.2} & \multirow{2}{*}{$\mathrm{CH}_{2}$} & $2.25(\mathrm{~m})$ & \multirow{2}{*}{ C-5, 9, 17} \\
\hline & & & $1.61(\mathrm{~m})$ & \\
\hline 8 & 49.1 & $\mathrm{CH}$ & $2.30(\mathrm{~m})$ & $C-6,10$ \\
\hline 9 & 36.5 & $\mathrm{C}$ & & \\
\hline 10 & 44.6 & $\mathrm{CH}$ & $2.20(\mathrm{~m})$ & $\begin{array}{c}\mathrm{C}-1,2,4,5,6, \\
8,11\end{array}$ \\
\hline \multirow{2}{*}{11} & \multirow{2}{*}{40.8} & \multirow{2}{*}{$\mathrm{CH}_{2}$} & $2.30(\mathrm{dd}, 14.8,4.0 \mathrm{~Hz})$ & C-8, 10, 12, \\
\hline & & & $1.73(\mathrm{dd}, 14.812 .0 \mathrm{~Hz})$ & 13 \\
\hline 12 & 70.3 & $\mathrm{CH}$ & $5.42(\mathrm{dd}, 12.4,4.0 \mathrm{~Hz})$ & $\mathrm{C}-13,14,16$ \\
\hline 13 & 125.0 & $\mathrm{C}$ & & \\
\hline 14 & 108.4 & $\mathrm{CH}$ & $6.42(\mathrm{~s})$ & $\mathrm{C}-13,15,16$ \\
\hline 15 & 143.8 & $\mathrm{CH}$ & $7.43(\mathrm{~s})$ & $\mathrm{C}-13,14,16$ \\
\hline 16 & 139.6 & $\mathrm{CH}$ & $7.47(\mathrm{~s})$ & $\mathrm{C}-13,14,15$ \\
\hline 17 & 171.6 & $\mathrm{C}$ & & \\
\hline 19 & 28.7 & $\mathrm{CH}_{3}$ & $1.30(\mathrm{~s})$ & $\mathrm{C}-4,5,6,10$ \\
\hline 20 & 26.9 & $\mathrm{CH}_{3}$ & $0.96(\mathrm{~s})$ & C- $8,9,10,11$ \\
\hline
\end{tabular}

The ${ }^{1} \mathrm{H}$-NMR and ${ }^{13} \mathrm{C}$-NMR data of $\mathbf{1}$ are very similar to those of tinocallone $\mathrm{C}$ [9] that has been isolated from the roots of Tinospora capillipes. The main difference between these two compounds is the chemical shifts of $\mathrm{C}-2, \mathrm{C}-3$, and $\mathrm{C}-4$ in ring $\mathrm{A}$ in the ${ }^{1} \mathrm{H}-\mathrm{NMR}$ and ${ }^{13} \mathrm{C}-\mathrm{NMR}$ spectra, which are $\delta$ $112.4(\mathrm{C}-2), 145.7$ (C-3), $198.9(\mathrm{C}-4)$, and $\delta 5.86(\mathrm{~m}, \mathrm{H}-2)$ in compound 1, and $\delta 145.5(\mathrm{C}-2)$, 128.3 (C-3), 200.8 (C-4), and $\delta 6.87$ (m, H-2), 5.87 (dd, $J=10.2,2.2 \mathrm{~Hz}, \mathrm{H}-3$ ) in tinocallone C [9], indicating that $\mathrm{C}-3$ was substituted by hydroxyl group. In the HMBC spectrum (Figure 2), the correlations between $\mathrm{H}-2(\delta 5.86, \mathrm{~m})$ and $\mathrm{C}-4(\delta 198.9), \mathrm{CH}_{3}-19(\delta 1.30 \mathrm{~s})$ and $\mathrm{C}-4, \mathrm{H}-1$ ( $\delta$ 2.87, 2.30, each $\mathrm{m})$ and $\mathrm{C}-3(\delta$ 145.7), H-2 $(\delta 5.86, \mathrm{~m})$ and $\mathrm{C}-3(\delta$ 145.7), further confirmed the hydroxyl group at $\mathrm{C}-3$. The position of $\gamma$-lactone group was also confirmed by the HMBC correlations observed from $\mathrm{H}$ $12(\delta 5.42)$ to $\mathrm{C}-13(\delta 125.0), \mathrm{C}-14(\delta 108.4)$ and $\mathrm{C}-16(\delta$ 139.6) in the HMBC spectrum. The relative configuration of 1 was deduced by a ROESY analysis. The key correlation between $\mathrm{CH}_{3}-9$ and $\mathrm{H}-8$ 
indicated that these were on the same orientation of the molecule, and were tentatively assumed as $\beta$-oriented. Similarly, the $\alpha$-orientations of $\mathrm{H}-10, \mathrm{H}-12$ and $\mathrm{CH}_{3}-5$ were elucidated from the correlations between $\mathrm{H}-10$ and $\mathrm{CH}_{3}-5$, and $\mathrm{H}-10$ and $\mathrm{H}-12$. The relative configuration of these positions remained the same as those in tinocallone $\mathrm{C}$ [9]. The spectral data of 1 were completely assigned using HSQC, ${ }^{1} \mathrm{H}_{-}{ }^{1} \mathrm{H}$ COSY, HMBC and ROESY experiments. Thus, on the basis of above spectral data, compound 1 was identified as a new 18-norclerodane diterpenoid and named sagitone (Figure 2).

Figure 2. The key HMBC correlations of compound 1.

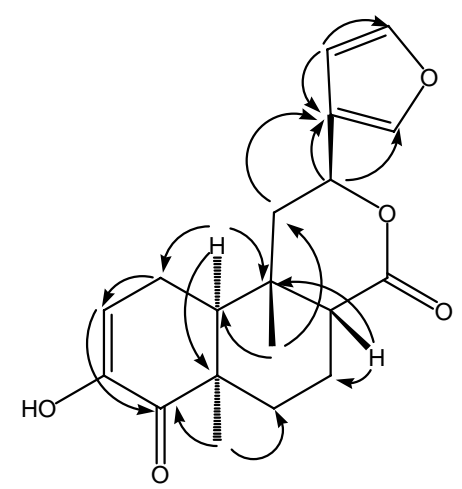

\section{Experimental}

\subsection{General}

All reagents were analytical grade and water was distilled twice. TLC was preformed with silica gel $\mathrm{GF}_{254}$ (Marine Chemical Industry Factory, Qingdao, China), and the spots were visualized by spraying with $10 \% \mathrm{H}_{2} \mathrm{SO}_{4} / \mathrm{EtOH}$ reagent. Column chromatography was performed using silica gel (Marine Chemical Industry Factory, Qingdao, China), reverse-phase $\mathrm{C}_{18}$ silica gel (Merck, Germany) and Sephadex LH-20 (Sigma). Melting points were measured with an X-4 melting point apparatus and are uncorrected. Optical rotations were recorded on a Perkin-Elmer 241 polarimeter. UV spectra were obtained on a Perkin-Elmer Lambda 900 UV/VIS/NIR spectrophotometer. IR spectra were obtained on a Perkin-Elmer 577 spectrometer with $\mathrm{KBr}$ pellets. NMR Spectra were recorded on a Bruker AV-400 spectrometer $\left({ }^{1} \mathrm{H}, 400 \mathrm{MHz} ;{ }^{13} \mathrm{C}, 100 \mathrm{MHz}\right)$, and chemical shifts are presented as values relative to tetramethylsilane as an internal standard. Low-resolution electrospray-ionization mass spectrometry (ESI-MS) and HR-ESI-MS were recorded on a Finnigan LCQ-Advantage mass spectrometer and a VG Auto-Spec-3000 mass spectrometer.

\subsection{Plant material}

The dried roots of Tinospora sagittata var. yunnanensis were collected in November 2007 from Honghe County, Yunnan Province, China. The plant was authenticated by professor Shao-Bin Ma, Department of Biology, Yunnan University. A voucher specimen (TSY200711) was deposited in the herbarium of the School of Chemistry and Biotechnology, Yunnan University of Nationalities, Kunming, China. 


\subsection{Extraction and isolation}

The dried roots $(10.0 \mathrm{Kg})$ of $T$. sagittata var. yunnanensis were extracted with $95 \%$ ethanol $(60 \mathrm{~L} \times$ 3) for $48 \mathrm{~h}$ each at room temperature, and combined extract was concentrated under vacuum to give a brown residue $(1,000 \mathrm{~g})$. The residue was then suspended in water $(1.5 \mathrm{~L})$ and extracted with EtOAc $(1.5 \mathrm{~L} \times 5)$, and $n-\mathrm{BuOH}(1.5 \mathrm{~L} \times 5)$ to give the corresponding EtOAc $(250 \mathrm{~g}), n-\mathrm{BuOH}$ extract $(380 \mathrm{~g})$, and water extract (350 g), respectively.

A part of EtOAc extract (75 g) was subjected to silica gel column chromatography and eluted with a gradient of petroleum ether-MeOH (50:1-0:1, v/v) to afford five fractions (Fr. 1-5). Fr. 3 (5.0 g) was chromatographed on Sephadex LH-20 column using $\mathrm{CHCl}_{3}-\mathrm{MeOH}(1: 1, \mathrm{v} / \mathrm{v})$ as eluent to give compound 1 (15 mg).

A part of the $n$-BuOH extract (50 g) was subjected to silica gel column chromatography using a stepwise gradient elution of $\mathrm{CHCl}_{3}-\mathrm{MeOH}(20: 1-2: 1)$ to obtain eight fractions (Fr. 1-8). Fr. 1 (8.0 g) was further purified over Sephadex LH-20 column eluted by $\mathrm{MeOH}$, and then recrystallized in $\mathrm{CHCl}_{3}$ to give compound 2 (13 mg). Fr. 2 (6.2 g) was rechromatographed over silica gel column eluted by gradient EtOAc-MeOH (1:0-10:1) to afford compounds $5(120 \mathrm{mg})$ and 6 (80 mg). Fr. 3 (4.7 g) was subsequently subjected to Sephadex LH-20 (eluted with $\mathrm{MeOH}$ ) and ODS (eluted with 1\% $\mathrm{MeOH}$ in water ) column chromatography, followed by purification over silica gel column chromatography with EtOAc-MeOH (1:0-6:1) as mobile phase to yield compound 3 (50 mg). Compound 4 was collected from Fr. 5 (5.8 g) by ODS (eluted with $20 \% \mathrm{MeOH}$ ) and silica gel column chromatography (eluted with EtOAc-MeOH; 1:0-8:1).

\subsection{Characterization of compound $\mathbf{1}$}

Sagitone (1): Amorphous powder, M.p. $185-186^{\circ} \mathrm{C} ;[\alpha]_{D}^{25}=-4.8^{\circ}\left(c=0.68, \mathrm{CHCl}_{3}\right)$; UV (MeOH): $\lambda_{\max }\left(\log \varepsilon_{\max }\right): 238(1.86), 325(1.26) \mathrm{nm}$; IR (KBr): $v=3,407,3,148,1,710,1,672,1,655,1,503$, 1,403, 1,300, 1,164, 1,082, $874 \mathrm{~cm}^{-1}$; ESI-MS: $m / z=331[\mathrm{M}+\mathrm{H}]^{+}, 683[2 \mathrm{M}+\mathrm{Na}]^{+}$; HR-ESI-MS: $m / z=331.3816$ (calcd. 331.3829 for $\mathrm{C}_{19} \mathrm{H}_{23} \mathrm{O}_{5},[\mathrm{M}+\mathrm{H}]^{+}$), $683.2856[2 \mathrm{M}+\mathrm{Na}]^{+} ;{ }^{1} \mathrm{H}-$ and ${ }^{13} \mathrm{C}-\mathrm{NMR}$ : see Table 1 .

\subsection{Bioassay}

Inhibition of cell-growth activity was determined by a MTT assay using human chronic myelogenous leukemia cells (K562) and human promyelocytic leukemia cells (HL-60) as previously described [10]. cis-Diamminedichloroplatinum (DDP) was used as a positive control. None of the compounds showed any obvious cytotoxic effect against cancer cell lines K562 and HL-60 at a concentration of $10 \mu \mathrm{M}$.

\section{Conclusions}

Repeated column chromatography (including normal-phase and reverse-phase silica gel, and Sephadex LH-20) of the dry roots of T. sagittata var. yunnanensis has led to the isolation of a new clerodane-type diterpenoid, named sagitone (1), together with the five known diterpenoids columbin (2), palmatoside C (3), fibleucin (4), tinophylloloside (5), and epitinophylloloside (6). The structure of 
the new compound 1 was determined by spectroscopic methods including 1D NMR, 2D NMR and MS experiment, and the structures of the known compounds including 2 $\mathbf{6}$ were identified by comparing their NMR data with those of ones in the literature. None of the compounds showed any significant cytotoxic activity against the cancer cell lines K562 and HL-60 at a concentration of $10 \mu \mathrm{M}$.

\section{Acknowledgements}

This investigation was financially supported by the Key Project of Chinese Ministry of Education (No. 209116) and the Science Foundation of the Education Department of Yunnan Province (No. 07Y41403). We are grateful to School of Chemistry and Biotechnology, Yunnan Nationalities University for measuring NMR and MS spectra. We also thank Key Laboratory of Medicinal Chemistry for Natural Resource, Ministry of Education, Yunnan University for the cell cultivation and bioactivity tests.

\section{References and Notes}

1. Hanson, J.R. Diterpenoids. Nat. Prod. Rep. 2007, 24, 1332-1341.

2. Castro, A.; Coll, J. Neo-clerodane diterpenoids from Verbenaceae: Structural elucidation and biological activity. Nat. Prod. Commun. 2008, 3, 1021-1031.

3. Coll, J.; Tandron, Y.A. Neo-clerodane diterpenoids from Ajuga: Structural elucidation and biological activity. Phytochem. Rev. 2007, 7, 25-49.

4. Kabouche, A.; Kabouche, Z. Bioactive diterpenoids of Salvia species. Stud. Nat. Prod. Chem. 2008, 35, 753-834.

5. Maurya, R.; Wazir, V.; Kapil, R.S. Biotherapeutic diterpene glucosides from Tinospora species. J. Indian Chem. Soc. 1994, 71, 361-364.

6. Pathak, S.K.; Jain, D.C.; Sharma, R.P. Chemistry and biological activities of the Genera Tinospora. Pharm. Biol. 1995, 33, 277-287.

7. Jiangsu New Medical College. The Dictionary of Traditional Chinese Medicine; People's Publishing House: Shanghai, China, 1986; pp. 1393-1394.

8. Cheng, C.M.; Dai, Y.; Huang, X.Z.; Zhu, Y.; Dai, J.H.; Liu, X.F.; Wang, J. Chemical constituents from roots of Tinospora sagittata var. yunnanensis. Chin. Tradit. Herb. Drug. 2010, 41, 689-692.

9. Song, C.Q.; Xu, R.S. New clerodane diterpenoids from Tinospora capillipes. Chin. Chem. Lett. 1992, 3, 185-188.

10. Fu, G.M.; Wang, Y.H.; Gao, S.; Tang, M.H.; Yu, S.S. Five new cytotoxic triterpenoid saponins from the roots of Symplocos chinensis. Planta Med. 2005, 71, 666-672.

Sample Availability: Samples of compounds 1-6 are available from the authors.

(C) 2010 by the authors; licensee MDPI, Basel, Switzerland. This article is an open access article distributed under the terms and conditions of the Creative Commons Attribution license (http://creativecommons.org/licenses/by/3.0/). 